\title{
Analysis of the Video Recordings of an Aborted Upward Leader at Daytime from a "Bolt-from-the-Blue" Discharge
}

\author{
Gaopeng $\mathrm{Lu}^{*}, 1,2$ and William Walden-Newman ${ }^{1,3}$
}

\author{
${ }^{I}$ Physics Department and Langmuir Laboratory, New Mexico Institute of Mining and Technology, Socorro, New Mexico, \\ 87801, USA \\ ${ }^{2}$ Now at Electrical and Computer Engineering Department, Duke University, Durham, North Carolina, 27708, USA \\ ${ }^{3}$ Now at Department of Physics and Engineering Physics, Stevens Institute of Technology, Hoboken, New Jersey, 07030, \\ USA
}

\begin{abstract}
In this paper we present the joint analysis of an unconnected upward leader serendipitously recorded by two digital cameras at daytime at a close distance of 7-9 $\mathrm{m}$. Time resolved lightning emissions in the very high frequency (VHF) band located by the New Mexico Tech Lightning Mapping Array (LMA) indicate that this leader was triggered by the negative stepped leader of a "bolt-from-the-blue" lightning flash with one single stroke, which was detected by two independent lightning detection networks with a peak current of $-43 \pm 6 \mathrm{kA}$. The recorded upward leader, however, was aborted at a distance of $\sim 140 \mathrm{~m}$ from the lightning stroke. The net charge carried by the recorded upward leader, and thus by definition its polarity, is positive. By analyzing two video frames that documented this upward leader at different times and its tortuous structure, we estimate its luminous width to be $2-6 \mathrm{~cm}$, roughly 10 times of the actual width of the longitudinal current region found in the literature. Electric field measurements on the ground and on a balloon-borne instrument indicate that in addition to transferring -6 to $-8 \mathrm{C}$ negative charge to ground, this flash also deposited net negative charge over the stroke location, partly through a subsequent negative leader that approached while didn't cause a ground stroke.
\end{abstract}

Keywords: Aborted upward leader, "bolt-from-the-blue" discharge, electric field, charge transfer.

\section{INTRODUCTION}

The upward-going junction leader in response to the downward moving leader plays a significant role in the attachment process that eventually leads to a cloud-toground (CG) return stroke (Golde [1]; Uman [2]). The upward leader, which may carry large peak currents of $\sim 10$ kA (Weidman and Krider [3]), also proves to be a newly discovered cause of lightning-associated deadly injury (Anderson [4]; Cooper [5, 6]). Characteristics of this process are of importance for the lightning protection design and have been obtained through both theoretical analyses (Morrow and Blackburn [7]; Becerra and Cooray [8]) and coordinated field measurements (Wang et al. [9]). In spite of prevalence in natural $\mathrm{CG}$ lightning flashes with varying multiplicities (i.e., the number of strokes in a flash), upward leaders have only been photographed, mostly at nighttime, when they initiated from trees, buildings, tall towers, or the natural terrain (e.g., Wang et al. [9]; McEachron and McMorris [10]; Orville [11]; Krider and Ladd [12]; Krider and Wetmore [13]), at varying distances from $30 \mathrm{~m}$ to 1.6 $\mathrm{km}$.

This writing presents the analysis of an upward leader and a following CG stroke serendipitously recorded by two Canon digital cameras at daytime near the Balloon Hangar

*Address correspondence to this author at the Electrical and Computer Engineering Department, Duke University, Durham, North Carolina, 27708, USA; Tel: 919-660-5232; Fax: 919-660-5293; E-mail: g146@duke.edu $\left(33.98201^{\circ} \mathrm{N},-107.18825^{\circ} \mathrm{W}\right)$ of Langmuir Laboratory in central New Mexico. To the best of our knowledge this is the closest video recording of an upward leader at daytime, and the concurrent electric field measurements available allow a joint analysis of the documented leader in lightning context. The lightning flash giving rise to a recorded upward leader is examined for the first time with the lightning observation from the New Mexico Tech Lightning Mapping Array (LMA) that locates the individual sources of impulsive radio emissions in the very high frequency (VHF, 60-66 MHz) band (Rison et al. [14]; Thomas et al. [15]). Data from other sources using the GPS time for synchronization, such as a balloon-borne instrument that measures electric field changes above the storm and two ground-based networks that detect lightning strokes, provide additional information concerning the lightning discharge of our interest.

\section{VIDEO RECORDING AND DATA}

On the afternoon of 26 July 2006, two Canon digital cameras were operated outside the Balloon Hangar (the hangar, hereinafter) and were both directed toward north to record distant lightning strokes from a small active storm over Magdalena Mountains. A Powershot S2IS digital camera, equipped with a $0.5 \mathrm{X}$ wide angle lens, was operated in movie mode to capture images with $640 \times 480$ resolution at a speed of 30 frames per second (fps). A Powershot A400 digital camera obtained lower resolution $(320 \times 240)$ images at $15 \mathrm{fps}$. S2IS also recorded the 16-bit acoustic signal at a sampling frequency of about $44 \mathrm{kHz}$. At about 20:54:32 by the internal system clock of S2IS, both cameras recorded an 
upward leader that has motivated the work presented in this writing.

It was found later that the system time of S2IS led the Coordinated Universal Time (UTC) by about 8 minutes. We have searched for the flash associated with the recorded upward leader using the LMA data acquired between 20:40 and 21:00 UT by plotting the distances (not shown) from the hangar to individual LMA sources in this interval. Only one flash was found to approach the hangar within a distance of $2 \mathrm{~km}$. The comparison with precipitation reflectivity data from the NEXRAD radar located in Albuquerque (New Mexico) indicates this flash was produced in a small storm cell to the north of a much larger cell that produced all the other flashes in the selected interval.

In addition to the time resolved VHF images of lightning flashes mapped by the LMA, the ground electric fields were recorded by electric field mills deployed at South Baldy (SB) peak, the hangar $(\mathrm{BH})$, and Annex building (AB). The vector electric field changes at thundercloud altitudes caused by lightning discharges were recorded at $10 \mathrm{kHz}$ by a balloonborne instrument (the Esonde) (Sonnenfeld et al. [16]). The convention used in this writing is that the electric force caused by a positive vertical electric field on a positive charge points upward. Both the Los Alamos Sferic Array (LASA) (Shao et al. [17]) and the U.S. National Lightning Detection Network (NLDN) (Cummins et al. [18]) detected a negative $\mathrm{CG}$ stroke from the flash associated with the recorded upward leader.

\section{ANALYSIS AND RESULTS}

\subsection{The Lightning Flash}

The LMA sources from the flash are plotted in Fig. (1), along with the flight trajectory of the Esonde that was then at $12 \mathrm{~km}$ altitude (above the mean sea level, hereinafter) and measured the vector electric field change $(\Delta E)$ caused by this flash. The vertical component of $\Delta \boldsymbol{E}$ (i.e., $\Delta E_{z}$ ) is plotted in Fig. (1b), and is used in the following discussion. (Analysis using two horizontal components gives the same result.) This flash initiated at an altitude of about $8 \mathrm{~km}$, as indicated by the first LMA source, which is marked with a " $\times$ " symbol in Fig. (1). In the subsequent $50 \mathrm{~ms}$, the initial development ascended to $\sim 9 \mathrm{~km}$ altitude and then the lightning channel progressed over a distance of $6-7 \mathrm{~km}$ toward the hangar, which is about $3.2 \mathrm{~km}$ above the mean sea level. The mean speed of this propagation, $\sim 1.2-1.4 \times 10^{5} \mathrm{~m} / \mathrm{s}$, and its copiousness in VHF emissions, are both characteristic of a negative stepped leader (Rison et al. [14]; Shao and Krehbiel [19]). The negative polarity of the lightning channel that approached the hangar is consistent with the positive vertical electric field variation measured by the Esonde above the flash origin, where net positive charge was deposited.

The approach of the negative stepped leader was followed by a negative return stroke detected by LASA at 20:46:52.9227 UTC $(20: 46: 52.922$ UTC by the NLDN), indicated by a " $\Delta$ " in Fig. (1a). The LASA peak current of this stroke is $-36.9 \mathrm{kA}$, in comparison with $-48.6 \mathrm{kA}$ reported by the NLDN. The vertical electric field measured at the Esonde didn't indicate a long continuing current enduring longer than $40 \mathrm{~ms}$ subsequent to the return stroke, typical for the first stroke in negative CG flashes (Rakov and
Uman [20]). However, it is apparent that the electric field exhibited a slow variation during the $\sim 10$-ms quiescence in the post-return stroke VHF emissions. We attribute this variation to the negative charge transfer from the leader channel to ground. With the assumption that the leaderstroke process has transferred negative charge from a cloud region centered at an altitude of $7.5-8 \mathrm{~km}$, approximately 2 $\mathrm{km}$ northeast of the balloon, we estimate the overall charge transfer to be -6 to $-8 \mathrm{C}$ using the vertical electric field change measured by the Esonde $\left(\Delta E_{z} \sim+2.5 \mathrm{kV} / \mathrm{m}\right.$, Fig. 1b). In our calculation the influence of the ground, which is assumed to be a perfect flat conductor at a mean altitude of $2.8 \mathrm{~km}$ above the sea level, is taken into account with a point image charge.

As shown in Fig. (1), most LMA sources after the stroke were confined in a relatively compact region, which was at $6.5-8 \mathrm{~km}$ altitudes and is thought to be the negative cloud charge region where the negative leader began. These VHF emissions originated mainly from the so-called recoil streamers that transferred negative charge toward the flash origin or further into the negative leader channel (Thomas et al. [15]; Shao and Krehbiel [19]). As indicated in Fig. (1b), some recoil streamers caused transient variations that are referred to as " $K$-changes" in the electric field (Uman [2]; Shao and Krehbiel [19]). For example, the second $K$-change was associated with a recoil streamer that appeared to start a negative breakdown propagating nearly along the path of the initial negative leader (see Fig. 1). Data from both LASA and the NLDN, however, indicated that this negative breakdown didn't terminate on ground to produce another stroke, and hence the multiplicity of the negative CG flash shown in Fig. (1) was one. The negative stepped leader mapped by the LMA before the one and only ground stroke has enhanced the electric field at the hangar to trigger the upward leader recorded by the cameras. Previous records of upward leaders usually lacked adequate concurrent measurements to deduce the polarity of the upward leader (e.g., Orville [11]; Krider and Ladd [12]). With the negative polarity of the causative lightning channel that approached the hangar, we deduce that the recorded upward leader carried net positive charge, and hence by definition its polarity was positive.

This negative single-stroke flash, with a moderate duration of $\sim 260 \mathrm{~ms}$ (i.e., the time between the first and the last LMA source shown in Fig. (1a)), is an example of an unusual type of $\mathrm{CG}$ discharge that begins with a negative leader initiating between the negative cloud charge region and an upper positive cloud region, where the negative leader progresses horizontally before heading toward ground. Rison et al. [14] and Thomas et al. [15] also reported LMA observations of such flashes in New Mexico thunderstorms. Although differing from normal negative $\mathrm{CG}$ lightning in flash development, this type of $C G$ flashes, classified as "bolt-from-the-blue" (BFB) discharges (Krehbiel et al. [21]), also transfers negative charge from the negative cloud region to ground. This is consistent with the electric field measurements at the Esonde. The three components of the Esonde measurement consistently indicated that negative charge was removed from the aforementioned negative cloud charge region. 

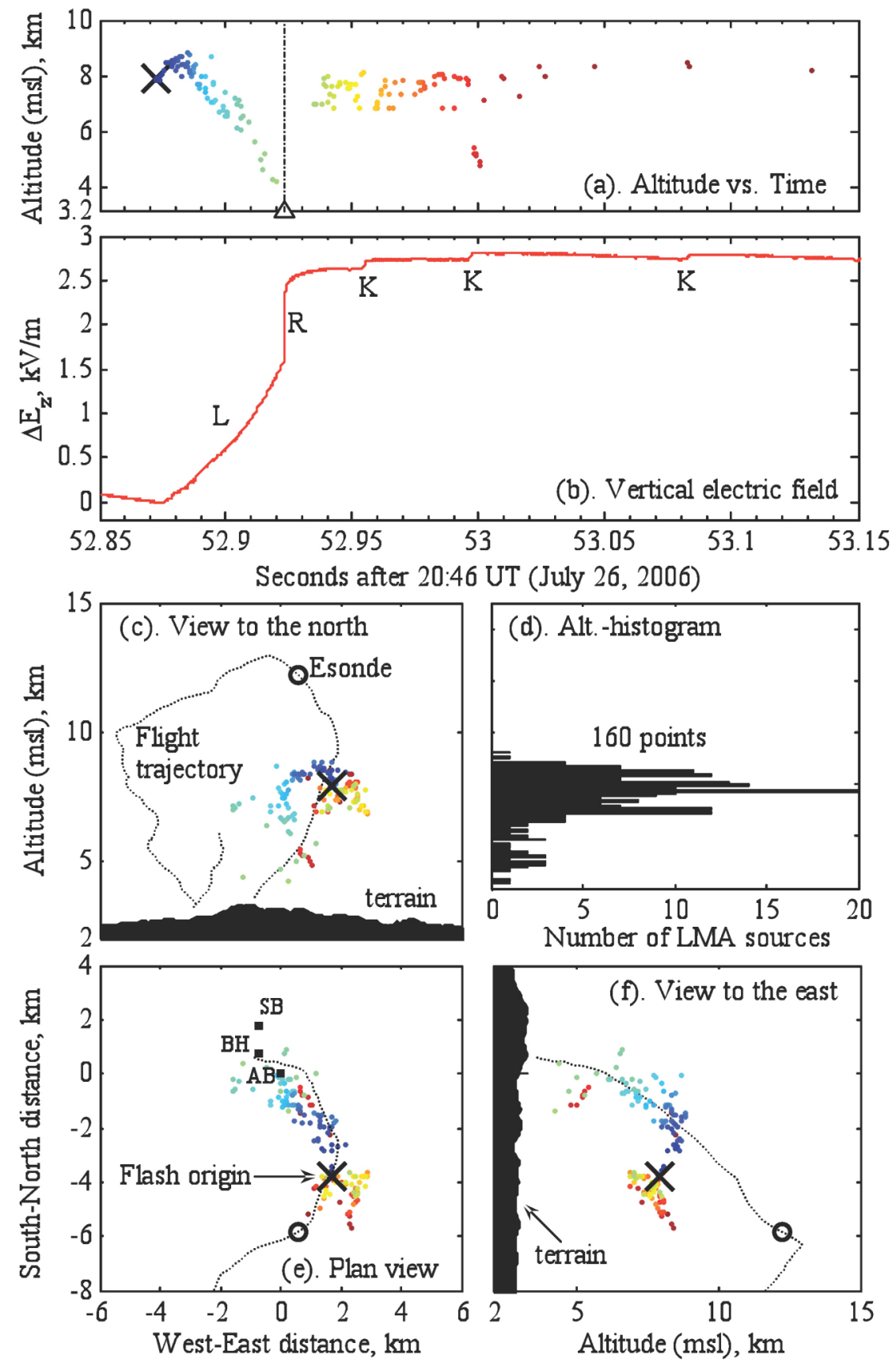

Fig. (1). The LMA sources and vertical electric field change (Panel b) measured by the Esonde from a "bolt-from-the-blue" discharge. LMA sources are color-coded by time, and are displayed in five panels: Panel a for altitude (above the mean sea level) as a function of time, Panel d for altitude histogram in 100-m bins, and three panels for the projections onto a west-east vertical plane (Panel c), a horizontal plane with the origin placed at Annex Building (Panel e), and a south-north vertical plane (Panel f). The " $\times$ " symbols mark the first LMA source that roughly represents the flash origin. In panel $a$ the negative return stroke detected by both LASA and the NLDN is indicated by a " $\Delta$ " symbol.

Within the 2-minute intervals before and after this flash, the ground electric fields at all the three stations indicated in Fig. (1e) were positive, indicative of the dominance by a negative cloud region. Although this flash struck ground near the hangar, none of these electric field mills, all being within $1 \mathrm{~km}$ from the stroke location, recorded large electric field deflections. The overall effect of this flash at the hangar, where ground electric field $\left(E_{G Z}\right)$ was measured at 10 $\mathrm{Hz}$, was to increase $E_{G Z}$ from $+4.4 \mathrm{kV} / \mathrm{m}$ to $+5.9 \mathrm{kV} / \mathrm{m}$ (i.e., $\Delta E_{G Z}=+1.5 \mathrm{kV} / \mathrm{m}$ ). The electric field recorded at the hangar showed variations that seem to be correlated in time with the first negative leader, the stroke, and then the second negative leader. Electric field changes caused by this flash at South Baldy peak and Annex Building were small $(<+1.0 \mathrm{kV} / \mathrm{m})$ while the polarity was definitely positive. Therefore, it appears that the negative charge removed from the negative cloud charge region by this flash was not only transferred to ground, but also deposited above the hangar, partly through the negative leader that followed the recoil streamer associated with the second $K$-change indicated in Fig. (1b). However, we also suspect that the charge carried by the first negative stepped leader was not completely transferred to 
ground by the ensuing stroke, which has been discussed by Krehbiel et al. [22] through an analysis of the ground electric fields measured with a slow antenna network with respect to the first strokes in several negative CG flashes.

\subsection{Video Frames of the Upward Leader and the Stroke}

Fig. (2) shows three video frames that contain images of the upward leader and the following stroke, and some interesting portions are zoomed in to show the details. We also calculate the spectrogram of the acoustic signal recorded by S2IS using short-time Fourier transform and the result is plotted in Fig. (3).

In Fig. (2a) and (2d), the recorded upward leader appears as a white faint stick that extends upward. At the time of this upward leader S2IS also recorded, nearly simultaneously, a sound of spark, as indicated in Fig. (3); this figure shows that the acoustic signal from the upward leader was recorded about $0.4 \mathrm{~s}$ before that from the stroke, indicating a distance of $\sim 140 \mathrm{~m}$ between the recorded upward leader and the stroke channel. The initiation point of the leader is not seen in the frame, while it should be somewhere on the ground between the cameras and a rock indicated in Fig. (2a). Fig. (2b) shows the later evolution of this leader with a long tortuous structure while branching is not observed. This upward leader failed to make connection (i.e., an aborted upward leader) with the downward stepped leader, which should have connected with another upward leader not captured by either camera, giving rise to the return stroke

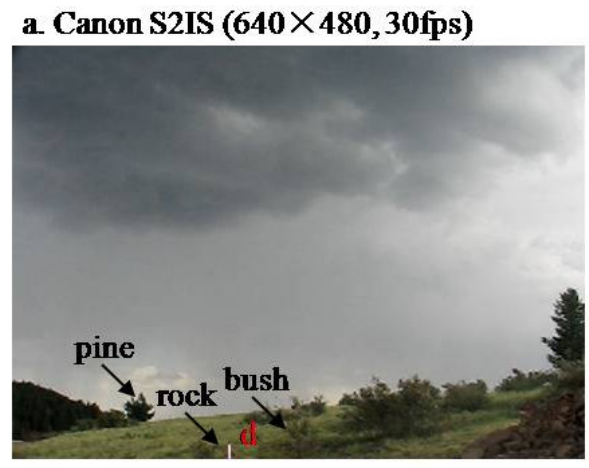

\section{b. Canon A400 (320 $\times 240,15 \mathrm{fps})$}
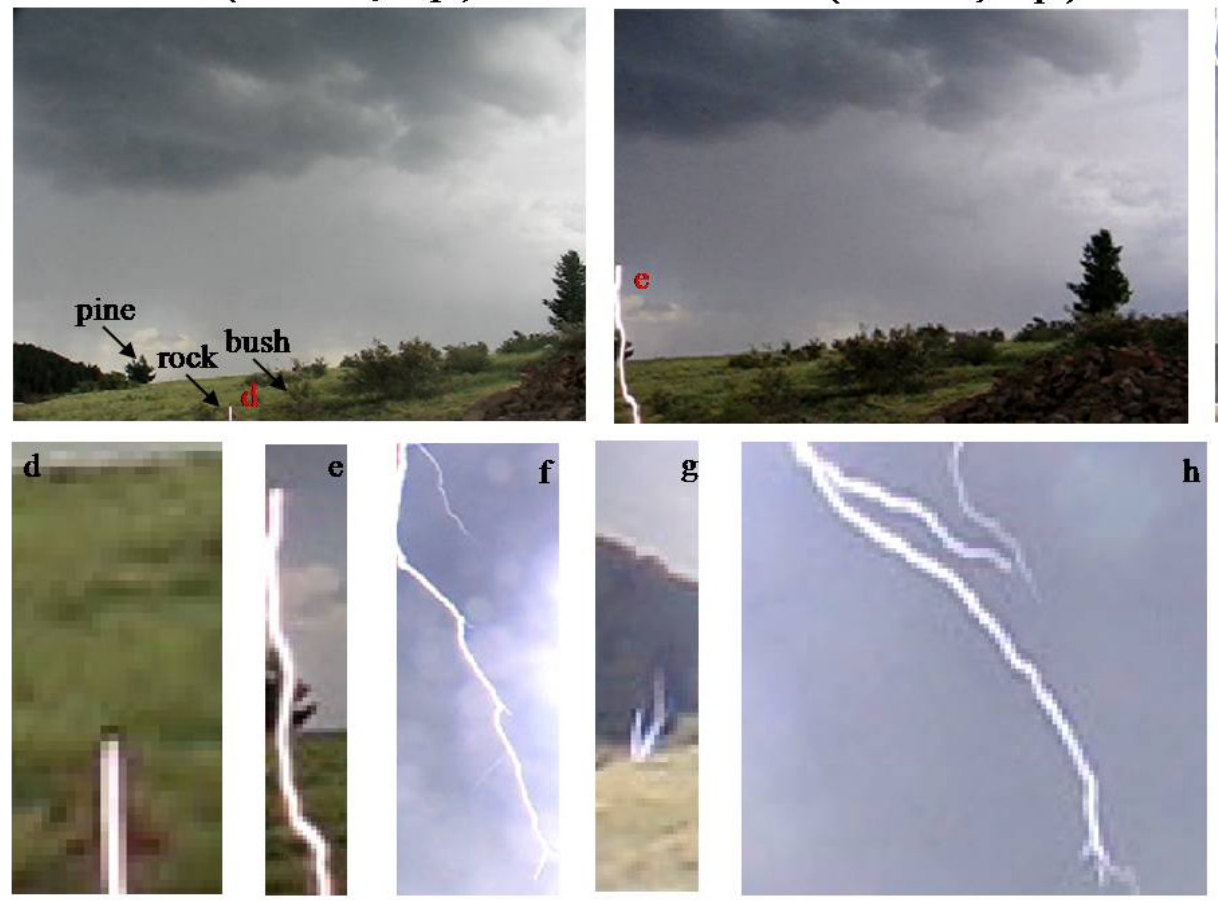

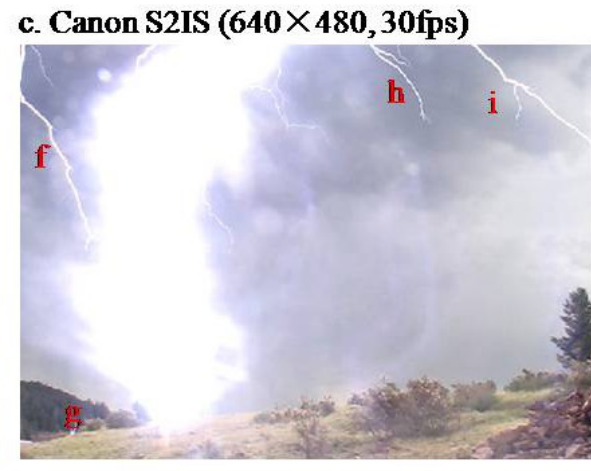

Fig. (2). Video frames from S2IS (Panels a and c) and A400 (Panel b) showing the images of a positive upward leader and the main stroke. Several interesting portions are indicated with letters and zoomed in to show the details (Panels $\mathbf{d}, \mathbf{e}, \mathbf{f}, \mathbf{g}, \mathbf{h}$, and $\mathbf{i}$ ).

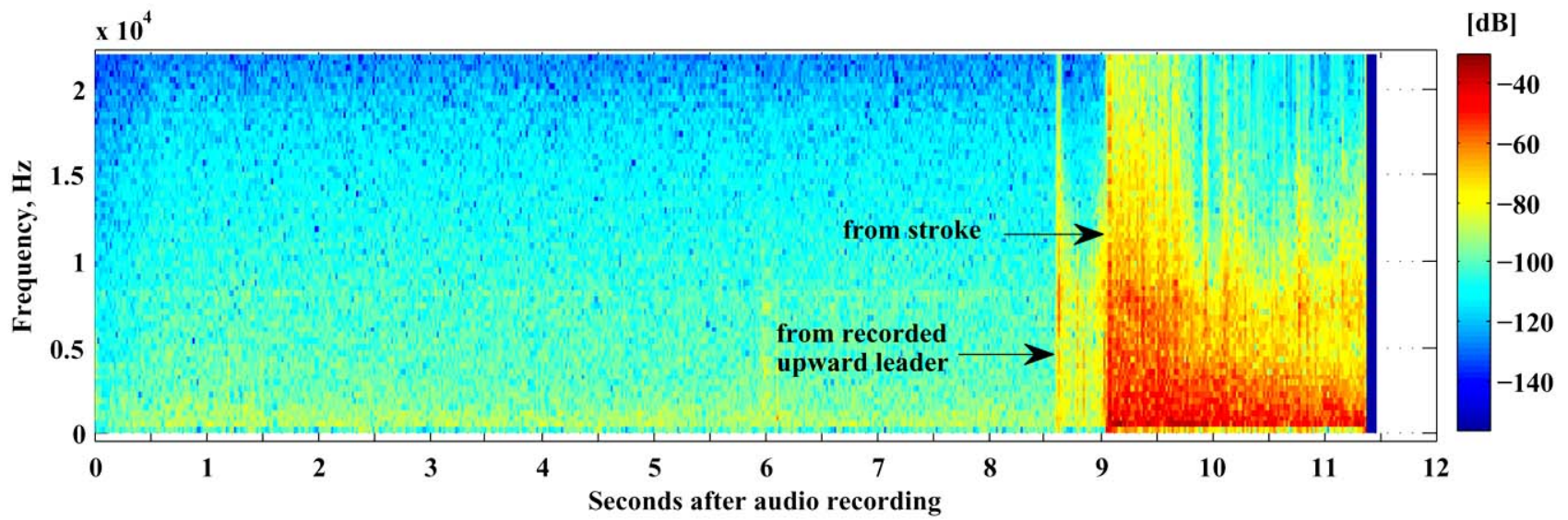

Fig. (3). Spectrogram of the acoustic signal recorded by S2IS. The spectrogram is calculated using the MATLAB ${ }^{\circledR}$ function SPECTROGRAM with a Hamming window of $23.2 \mathrm{~ms}$, which is equivalent to 1024 data points with a sampling frequency of $44.1 \mathrm{kHz}$. The time scale in this figure only represents the time since the camera (S2IS) began to record video frames and acoustic signals. 
only recorded by S2IS. Therefore, the recorded upward leader was an aborted (or an unconnected) upward leader (e.g., Uman [2]; Wang et al. [9]; Krider and Ladd [12]).

Fig. (2c) shows the video frame of the stroke, which hit the ground near a pine tree (indicated in Fig. 2a) about $4 \mathrm{~m}$ tall and $\sim 80 \mathrm{~m}$ from the cameras. The burst of thunder, which itself lasted $>2 \mathrm{~s}$ (see Fig. 3), lag behind the stroke flare by less than $0.4 \mathrm{~s}$ (i.e., the duration of twelve video frames recorded by S2IS), implying that the stroke point was within $\sim 60 \mathrm{~m}$ from the pine. The stroke channel that was photographed was about $40 \mathrm{~m}$ long, with a luminous width of a few meters. Most of the pixels that form the image of the stroke channel were saturated. As shown in Fig. (2g), S2IS also recorded another two aborted upward leaders that appeared to initiate from the same stem to the left of the pine, similar to the observation of Krider and Ladd [12] at nighttime; the visual lengths of these two leaders are estimated to be $0.5 \mathrm{~m}$ and $1 \mathrm{~m}$, respectively. It is possible that the acoustic signals from these leaders were also recorded by S2IS.

Several branches from the main stroke channel, probably other downward negative leaders that didn't reach ground, are visible in Fig. (2c) and are shown in Fig. (2f, h), and (2i). In negative $C G$ flashes, occasionally there are two or more downward negative stepped leaders that can connect to their corresponding upward positive leaders, giving rise to a forked return stroke consisting of multiple simultaneous terminations on ground (e.g., Wang et al. [23]; Ballarotti et al. [24]; Qie and Kong [25]).

\subsection{Width of the Upward Leader}

It is viable to estimate the luminous width $\left(D_{l}\right)$ of the recorded upward positive leader from the two frames shown in Fig. (2a) and (2c). Fig. (4) sketches our observation, with two cameras denoted as S (for S2IS) and A (for A400), respectively. Both cameras failed to show the upward leader initiation, and thus we could not deduce its exact distance from the cameras. However, by comparing with some landmarks for reference, such as the rock and the bush indicated in Fig. (2a), we first locate the upward leader initiation between $\mathrm{S}$ and the rock. By further seeking a location consistent with the observation of $\mathrm{A}$, we deduce that the most likely initiation point was around "+" shown in Fig. (4), approximately 7-9 $\mathrm{m}$ from $\mathrm{S}$.

We estimate $D_{l}$ by counting the number of pixels that contribute to its radial image. Note that the images shown in Fig. (2) were acquired using the movie mode of the digital camera that automatically controls the exposure time to avoid saturation. As shown in Fig. (2d), the radial image of this leader consists of 2 to 3 pixels along its longitudinal extension, in comparison with the number of pixel columns of 640 (for S2IS). At a distance of 7-9 m, the width of view field for $\mathrm{S}$ is about $6-8 \mathrm{~m}$, and therefore we estimate the luminous width of the upward leader to be $D_{l} \approx 2.8 \pm 0.9 \mathrm{~cm}$. For the leader shown in Fig. (2b), through a similar analysis we derive $D_{l} \approx 4.3 \pm 1.3 \mathrm{~cm}$ over a length of about $2 \mathrm{~m}$.

Estimates of the width of an upward leader have been rarely reported in the literature. By examining the photograph of a lightning flash striking a tree about $60 \mathrm{~m}$ from the camera, Orville [11] estimated the width of an upward leader, with polarity unknown, to be approximately 5 $\mathrm{cm}$ over a length of 8-10 $\mathrm{m}$, which is consistent with our estimates. A luminous width of several centimeters for the positive upward leader is comparable to the stroke channel diameters varying between 3 and $12 \mathrm{~cm}$ as deduced from photographs taken at a distance of $100 \mathrm{~m}$ (Evans and Walker [26]). Like the stroke channel and the negative stepped leader (Rakov and Uman p.134 [27]), the positive upward leader also consists of a thin, inner hot core surrounded by a corona sheath (Becerra and Cooray [8]; Bazelyan and Raizer p.204 [28]). In this case the luminous width of an upward leader estimated based upon the photographic technique is larger than the width of the longitudinal current region. By examining the holes caused by lightning on a fiberglass screen, Uman [29] attributed those holes with 2-3.5 cm diameter to return strokes; the rest with significantly smaller diameters of 2-5 mm, according to Loeb [30], were likely caused by aborted upward leaders or heavier branches.

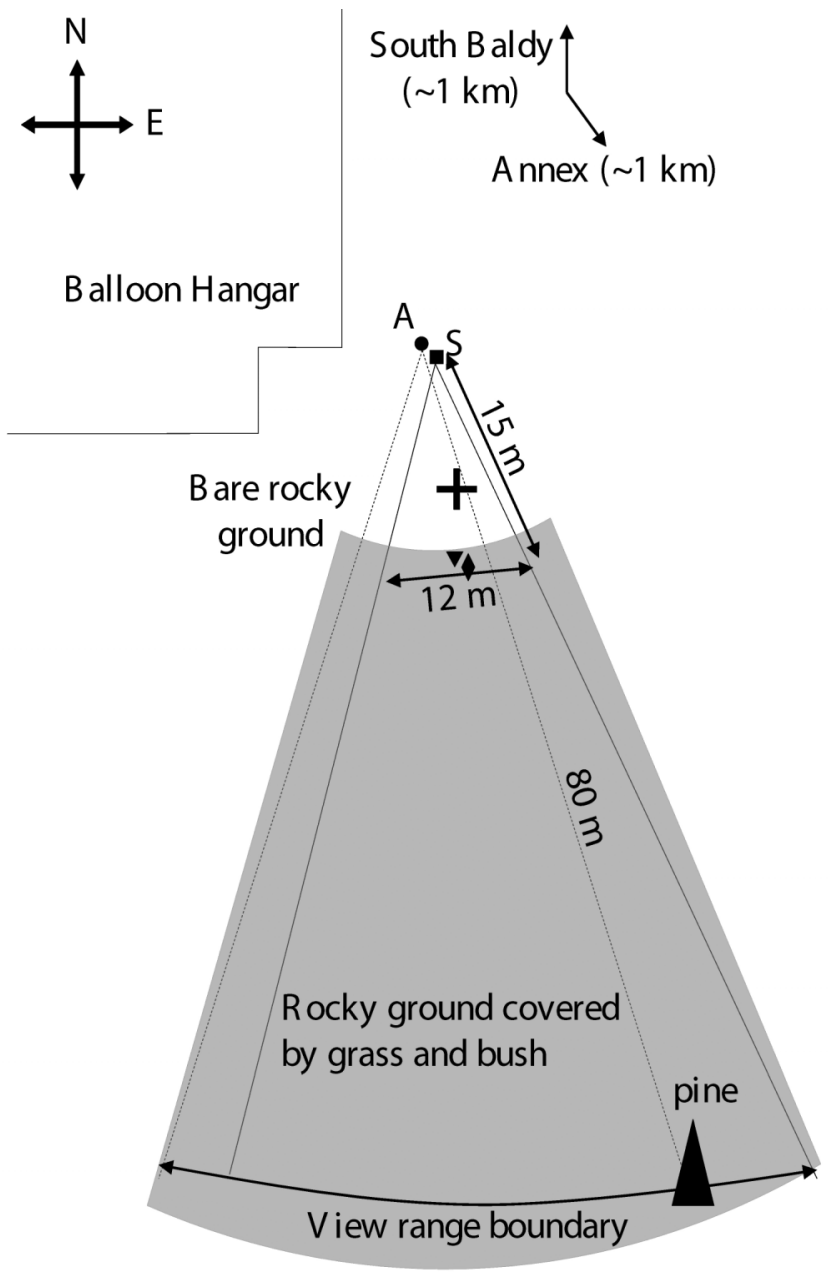

Fig. (4). Sketch map of the observation. The locations of two cameras are marked as S (for S2IS) and A (for A400), respectively. The landmarks for reference marked in Fig. (2a) are shown with a

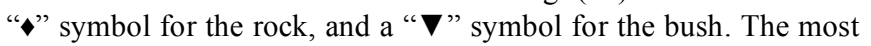
likely initiation point of the recorded upward leader is marked with a "+" symbol. The inferred stroke location is not shown. Distances are measured accurate to $5 \%$, and the figure is not plotted to scale.

\section{SUMMARY}

An upward leader and the following stroke were fortuitously recorded at daytime by two digital cameras that were both 
operated in movie mode. The rareness of such observations at a quite close distance (7-9 $\mathrm{m}$ from the cameras to the recorded upward leader) and the simultaneous measurements from various data sources make these recordings worthy of a joint analysis in the context of a lightning flash.

The lightning discharge associated with our recordings was a single-stroke negative $C G$ flash that went to the ground via the upper positive charge region, i.e., a "bolt-from-the-blue" discharge. The recorded upward leader was triggered when the negative stepped leader in this unusual flash approached the hangar to a close distance, and thus the polarity of this upward leader was positive. However, this upward leader was aborted at a distance of $\sim 140 \mathrm{~m}$ from the stroke, which was detected by two lightning detection networks with a peak current of $-43 \pm 6$ $\mathrm{kA}$. Using the balloon-borne electric field measurement above the cloud region where the flash initiated, we estimate the total charge transferred by this stroke to ground to be -6 to $-8 \mathrm{C}$. The ground-based and balloon-borne electric field measurements with respect to this flash indicated that in addition to a transfer to ground, net negative charge was also deposited over the place where the lightning struck ground, partly due to the second negative leader that followed the initial negative leader channel while eventually didn't produce a ground stroke.

The luminous width of the recorded upward leader is estimated to be between 2 and $6 \mathrm{~cm}$, about 10 times of the actual width of the longitudinal current region found in the literature.

\section{ACKNOWLEDGMENTS}

The video data were acquired during a project financially supported by grant ATM-0331164 from the National Science Foundation (NSF). William P. Winn is appreciated for valuable comments on the video recordings and assistance on data evaluations. Steven Hunyady provided assistance in analyzing the electric field mill data around Langmuir Laboratory. Harald Edens preprocessed the New Mexico Tech Lightning Mapping Array (LMA) data and Richard G. Sonnenfeld provided the access to the Esonde data. The authors are indebted to Jeremiah Harlin and Xuan-Min Shao from Los Alamos National Laboratory for the Los Alamos Sferic Array (LASA) data. Richard J. Blakeslee and Steven J. Goodman from Marshall Space Flight Center (MSFC) of the National Aeronautics and Space Administration (NASA) and Sherry Harrison from the Global Hydrology Resource Center (GHRC) are acknowledged for providing the U.S. National Lightning Detection Network (NLDN) data.

\section{REFERENCES}

[1] Golde RH. Occurrence of upward streamers in lightning discharges. Nature 1947; 160: 395-6.

[2] Uman MA. The Lightning Discharge. Orlando: Academic Press 1987.

[3] Weidman CD, Krider EP. The fine structure of lightning return stroke wave forms. J Geophys Res 1978; 83: 6239-47.
[4] Anderson RB. Does a fifth mechanism exist to explain lightning injuries? IEEE Eng Med Biol 2001; 20: 105-13.

[5] Cooper MA. A fifth mechanism of lightning injury. Acad Emerg Med 2002; 9: 172-4.

[6] Cooper MA. Distribution of lightning injury mechanisms. 20 International Lightning Detection ConferenceTucson, Arizona USA. 21-23 April 2008.

[7] Morrow R, Blackburn TR. The stepped nature of lightning, and the upward connecting streamer. J Phys D Appl Phys 2002; 35: 69-73.

[8] Becerra M, Cooray V. Time dependent evaluation of the lightning upward connecting leader inception. J Phys D Appl Phys 2006; 39: 4695-02.

[9] Wang D, Takagi N, Watanabe T, Sakurano H. Hashimoto M. Observed characteristics of upward leaders that are initiated from a windmill and its lightning protection tower. Geophys Res Lett 2008; 35(L02803).

[10] McEachron KB, McMorris WA. The lightning stroke Mechanism of discharge. Gen Elect Rev 1936; 39: 487-96.

[11] Orville RE. Photograph of a close lightning flash. Science 1968; 162: 666-7.

[12] Krider EP, Ladd CG. Upward streamers in lightning discharges to mountainous terrain. Weather 1975; 30: 77-81.

[13] Krider EP, Wetmore RH. Upward streamers produced by a lightning strike to radio transmission towers. J Geophys Res 1987; 92: 9859-62.

[14] Rison W, Thomas RJ, Krehbiel PR, Hamlin T, Harlin J. A GPS-based three-dimensional lightning mapping system Initial observations in central New Mexico. Geophys Res Lett 1999; 26: 3573-6.

[15] Thomas RJ, Krehbiel PR, Rison W, Hamlin T, Harlin J, Shown D. Observations of VHF source powers radiated by lightning. Geophys Res Lett 2001; 28: 143-6.

[16] Sonnenfeld RG, Battles JD, Lu G, Winn WP. Comparing E field changes aloft to lightning mapping data. J Geophys Res 2006; 111(D20209)

[17] Shao X, Stanley M, Regan A, Harlin J, Pongratz M, Stock M. Total lightning observations with the new and improved Los Alamos Sferic Array (LASA). J Atmos Oceanic Technol 2006; 23: 1273-88.

[18] Cummins KL, Murphy MJ, Bardo EA, Hiscox WL, Pyle RB, Pifer AE. A combined TOA/MDF technology upgrade of the US National Lightning Detection Network. J Geophys Res 1998; 103: 9035-44.

[19] Shao XM, Krehbiel PR. The spatial and temporal development of intracloud lightning. J Geophys Res 1996; 101: (26): 641-8.

[20] Rakov VA, Uman MA. Long continuing current in negative lightning ground flashes. J Geophys Res 1990; 95: 5455-70.

[21] Krehbiel PR, Riousset JA, Pasko VP, et al. Upward electrical discharges from thunderstorms. Nat Geosci 2008; 1: 233-7.

[22] Krehbiel PR, Brook M, McCrory RA. An analysis of the charge structure of lightning discharges to ground. J Geophys Res 1979; 84: 2432-56.

[23] Wang D, Takagi N, Watanabe T, Rakov VA, Uman MA. Luminosity waves in branched channels of two negative lightning flashes. J Atmos Elect 2000; 20: 91-7.

[24] Ballarotti MG, Saba MMF, Pinto Jr O. High-speed camera observations of negative ground flashes on a millisecond-scale. Geophys Res Lett 2005; 32(L23802).

[25] Qie X, Kong X. Progression features of a stepped leader process with four grounded leader branches. Geophys Res Lett 2007; 34(L06809).

[26] Evans WH, Walker RL. High-speed photographs of lightning at close range. J Geophys Res 1963; 68: 4455-61.

[27] Rakov VA, Uman MA. Lightning Physics and effects. New York: Cambridge Univ Press 2003.

[28] Bazelyan EM, Raizer YP. Spark discharge. New York: CRC Press, Boca Raton 1998.

[29] Uman MA. The diameter of lightning. J Geophys Res 1964; 69: 583-5.

[30] Loeb LB, Discussion of paper by MA Uman. The diameter of lightning. J Geophys Res 1964; 69: 587-9. 